\title{
COVID-19 in hematopoietic cell transplant recipients
}

\author{
Fevzi Altuntas ${ }^{1,2} \cdot$ Naim Ata ${ }^{3} \cdot{\text { Tugce Nur Yigenoglu }(1)^{1} \cdot \text { Semih Bascl }}^{1} \cdot$ Mehmet Sinan Dal $^{1} \cdot$ Serdal Korkmaz ${ }^{4}$. \\ Sinem Namdaroglu ${ }^{5}$ - Abdulkadir Basturk $\mathbb{1}^{6}$ - Tuba Hacıbekiroglu ${ }^{7} \cdot$ Mehmet Hilmi Dogu $^{8}$. ilhami Berber ${ }^{9}$.

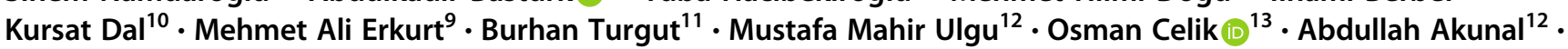 \\ Suayip Birinci ${ }^{14}$. On Behalf of Turkish Ministry of Health, Hematology Scientific Working Group
}

Received: 6 June 2020 / Revised: 22 September 2020 / Accepted: 1 October 2020 / Published online: 28 October 2020

(c) The Author(s), under exclusive licence to Springer Nature Limited 2020

\begin{abstract}
In this study, we aim to report the outcome of COVID-19 in hematopoietic cell transplant (HCT) recipients. HCT recipients $(n=32)$ with hematological disease and hospitalized for COVID-19 were included in the study. A cohort of age and comorbid disease-matched hospitalized COVID-19 patients with hematological malignancy but not underwent HCT $(n=$ $465)$, and another cohort of age and comorbid disease-matched hospitalized COVID-19 patients without cancer $(n=497)$ were also included in the study for comparison. Case fatality rate (CFR) was 5.6\% in patients without cancer, 11.8 in patients with hematological malignancy and $15.6 \%$ in HCT recipients. The CFR in HCT recipients who were not receiving immunosuppressive agents at the time of COVID-19 diagnosis was 11.5\%, whereas it was $33 \%$ in HCT recipients who were receiving an immunosuppressive agent at the time of COVID-19 diagnosis. In conclusion, our study reveals that for the current pandemic, HCT recipients, especially those receiving immunosuppressive drugs, constitute a special population of cancer patients.
\end{abstract}

SARS-CoV-2 spread all over the world rapidly and on March 11, 2020, it was declared a pandemic by the World Health Organization (WHO) [1-3]. Older age and comorbidities such as diabetes, hypertension, or cardiac disease are risk factors for a more aggressive clinical course in patients with COVID-19 [4]. In addition, in a previous report, it was reported that $39 \%$ of COVID-19 patients with cancer had severe events such as intensive care unit (ICU) admission, mechanical ventilation (MV) support and death during the COVID-19 course whereas only $8 \%$ of COVID19 patients without cancer had those severe events [5].

Hematopoietic cell transplantation (HCT) recipients are vulnerable to a variety of infections because of the high dose immunosuppressive agents they received to prevent graft failure. In addition, patients with hematological malignancy (HM) have varying degrees of immune

Members of the Turkish Ministry of Health, Hematology Scientific Working Group are listed above references.

Fevzi Altuntas

dr.faltuntas@gmail.com

Extended author information available on the last page of the article dysfunction. Therefore, these patients are immunocompromised and may be susceptible to a more aggressive course of COVID-19. In this study, we aim to report the outcome of COVID-19 in HCT recipients.

The data of laboratory-confirmed COVID-19 patients diagnosed between March 11, 2020 and May 29, 2020 included in the Republic of Turkey, Ministry of Health database, were analyzed retrospectively. As of May 29, 2020, there were 162.120 laboratory-confirmed COVID-19 cases in Turkey. All of the HCT recipients $(n=32)$ with hematological disease and hospitalized for COVID-19 were included in the study. A cohort of age and comorbid disease matched hospitalized COVID-19 patients with HM but not underwent HCT $(n=465)$, and another cohort of age and comorbid disease matched hospitalized COVID-19 patients without cancer $(n=497)$ were also included in the study for comparison.

Demographic and clinical characteristics of patients are given in Table 1. $20 \mathrm{HCT}$ recipients had autologous HCT (auto-HCT) and 12 had allogeneic HCT (allo-HCT). Nine $(75 \%)$ allo-HCT were performed from related donors and three $(25 \%)$ allo-HCT were performed from unrelated donors. Nine allo-HCT were from matched donors, whereas three allo-HCT were from a haploidentical donor. At the time of COVID-19 diagnosis, six (18.7\%) HCT recipients 
Table 1 Demographic and clinical characteristics of the groups.

Table 2 Outcome of COVID-19 in each group.

\begin{tabular}{|c|c|c|c|c|c|}
\hline \multicolumn{2}{|c|}{$\begin{array}{l}\text { Demographic and clinical } \\
\text { characteristics }\end{array}$} & $\begin{array}{l}\text { HCT recipients } \\
(n=32)\end{array}$ & $\begin{array}{l}\text { Patients with } \\
\text { Hematological } \\
\text { Malignancy }(n=465\end{array}$ & $\begin{array}{l}\text { Patients without } \\
\text { cancer }(n=497)\end{array}$ & $p$ value \\
\hline \multicolumn{6}{|l|}{ Gender } \\
\hline \multicolumn{2}{|l|}{ Male, $n(\%)$} & $25(78.1 \%)$ & $250(53.8 \%)$ & $269(54.1 \%)$ & $0.03^{\mathrm{a}}$ \\
\hline \multicolumn{2}{|l|}{ Female, $n(\%)$} & $7(21.9 \%)$ & $215(46.2 \%)$ & $228(45.9 \%)$ & \\
\hline \multicolumn{2}{|c|}{ Median age (years) } & $56,5(19-74)$ & $57(18-93)$ & $55(19-87)$ & 0.3 \\
\hline \multicolumn{6}{|c|}{ Comorbidity, $n(\%)$} \\
\hline \multicolumn{2}{|c|}{ Diabetes Mellitus } & $7(21.9 \%)$ & $111(23.9 \%)$ & $114(22.9 \%)$ & 0.9 \\
\hline \multicolumn{2}{|l|}{ Hypertension } & $18(56.3 \%)$ & $201(43.2 \%)$ & $200(40.2 \%)$ & 0.2 \\
\hline \multicolumn{2}{|c|}{ Cardiovascular diseases } & $5(15.6 \%)$ & $69(14.8 \%)$ & $63(12.7 \%)$ & 0.6 \\
\hline \multicolumn{2}{|c|}{ Respiratory system diseases } & $10(31.3 \%)$ & $86(18.5 \%)$ & $86(17.3 \%)$ & 0.1 \\
\hline \multicolumn{6}{|c|}{ Additional Treatment, $n(\%)$} \\
\hline \multicolumn{2}{|l|}{ Favipiravir } & $12(37.5 \%)$ & $131(28.2 \%)$ & $128(25.8 \%)$ & 0.3 \\
\hline \multicolumn{2}{|l|}{ Oseltamivir } & $12(37.5 \%)$ & $209(44.9 \%)$ & $222(44.7 \%)$ & 0.7 \\
\hline \multicolumn{2}{|c|}{ Lopinavir/ritonavir } & $2(6.3 \%)$ & $23(4.9 \%)$ & $12(2.4 \%)$ & 0.1 \\
\hline \multicolumn{2}{|c|}{ Hydroxychloroquine } & $24(75 \%)$ & $336(72.3 \%)$ & $352(70.8 \%)$ & 0.8 \\
\hline \multicolumn{2}{|c|}{ High dose vitamin $\mathrm{C}$} & $8(25 \%)$ & $81(17.4 \%)$ & $69(13.9 \%)$ & 0.1 \\
\hline \multicolumn{6}{|c|}{ aAll hematological malignancies vs patients without cancer; $p=0.7$. } \\
\hline Factors & $\begin{array}{l}\text { HCT } \\
\text { recipients }\end{array}$ & \multicolumn{2}{|c|}{$\begin{array}{l}\text { Patients with Hematological } \\
\text { Malignancy }\end{array}$} & $\begin{array}{l}\text { Patients without } \\
\text { cancer }\end{array}$ & $p$ value \\
\hline Hospital stay & 13 days & \multicolumn{2}{|l|}{10 days } & 10 days & 0.2 \\
\hline ICU stay & 12 days & \multicolumn{2}{|l|}{6 days } & 7 days & 0.25 \\
\hline $\begin{array}{l}\text { ICU admission, } \\
n(\%)\end{array}$ & $7(21.9 \%)$ & \multicolumn{2}{|c|}{$98(21.1 \%)$} & $56(11.3 \%)$ & 0.001 \\
\hline $\mathrm{MV}, n(\%)$ & $5(15.6 \%)$ & \multicolumn{2}{|c|}{$70(15.1 \%)$} & $36(7.2 \%)$ & 0.001 \\
\hline \multicolumn{6}{|c|}{ COVID-19 Severity, $n(\%)$} \\
\hline Severe & $7(21.9 \%)$ & \multicolumn{2}{|c|}{$78(16.8 \%)$} & $65(13.1 \%)$ & 0.001 \\
\hline Critical & $4(12.5 \%)$ & \multicolumn{2}{|l|}{$65(14 \%)$} & $33(6.6 \%)$ & \\
\hline $\mathrm{CFR}, n(\%)$ & $5(15.6 \%)$ & \multicolumn{2}{|c|}{$55(11.8 \%)$} & $28(5.6 \%)$ & 0.001 \\
\hline
\end{tabular}

$C F R$ case fatality rate, $M V$ mechanical ventilation, $I C U$ intensive care unit. were receiving immunosuppressive drugs (four patients were receiving cyclosporine and two patients were receiving tacrolimus). Among COVID-19 patients who were performed auto-HCT; there were 11 multiple myeloma (MM), 7 non-Hodgkin lymphoma (NHL) and 2 Hodgkin lymphoma (HL) patients. Among allo-HCT recipients with COVID-19, there were five acute myeloid leukemia (AML), three acute lymphoblastic leukemia (ALL), three chronic myeloid leukemia (CML) and one aplastic anemia (AA) patients. In the HM group, there were $222 \mathrm{NHL}, 73 \mathrm{MM}, 54$ chronic lymphocytic leukemia (CLL), 38 AML, 29 CML, $25 \mathrm{HL}, 15$ ALL and 9 hairy cell leukemia (HCL) patients.

Outcome of COVID-19 in each group is given in Table 2. $21.9 \%$ of the HCT recipients had severe disease and $12.5 \%$ were critically ill. In the post hoc analysis, the rate of severe and critical disease was significantly higher in patients with HM compared with patients without cancer however there was no significant difference between patients with $\mathrm{HM}$ and $\mathrm{HCT}$ recipients regarding the rate of severe and critical disease.

The rates of MV support and ICU admission were significantly different between groups $(p=0.001, p=0.001)$. $21.9 \%$ of HCT recipients were admitted to ICU during the course of COVID-19, and $15.6 \%$ of HCT recipients needed MV support during the course of COVID-19. In post-hoc analysis the rate of ICU admission and MV support was significantly higher in patients with HM compared with patients without cancer however there was no significant difference between patients with HM and HCT recipients regarding the rate of ICU admission and MV support. When 
Table 3 Characteristics of deceased HCT patients.

\begin{tabular}{|c|c|c|c|c|c|c|c|}
\hline & Gender-Age & Diagnosis-Year & Comorbidity & Antiviral & Hospitalization (days) & ICU (days) & IST \\
\hline Patient one & M-31 & AA-2019 & - & $\mathrm{Fa}$, & 6 & - & Cyclosporine \\
\hline Patient two & M-36 & CML-2019 & - & $\mathrm{Fa}, \mathrm{H}, \mathrm{C}$ & 6 & 5 & Cyclosporine \\
\hline Patient three & $\mathrm{F}-55$ & MM-2020 & HT & $\mathrm{H}, \mathrm{L}, \mathrm{A}$ & 9 & 3 & - \\
\hline Patient four & M-57 & MM-2019 & CAD, HT, DM & $\mathrm{Fa}, \mathrm{H}, \mathrm{O}$ & 12 & 12 & - \\
\hline Patient five & M-57 & MM-2019 & COPD, CAD, HT & $\mathrm{Fa}, \mathrm{H}, \mathrm{A}, \mathrm{O}$ & 39 & 37 & - \\
\hline
\end{tabular}

$A A$ aplastic anemia, $C M L$ chronic myeloid leukemia, $M M$ multiple myeloma, $C A D$ coronary artery disease, $C O P D$ chronic obstructive pulmonary disease, $H T$ hypertension, $D M$ diabetes mellitus, $F a$ Favipiravir, $H$ hydroxychloroquine, $L$ lopinavir, ritonavir, $C$ high dose vitamin $C$, $A$ azithromycin, $O$ Oseltamivir, ICU intensive care unit, IST immunosuppressive treatment.

auto-HCT recipients were compared with allo-HCT recipients, no significant difference was observed regarding rate of MV support, ICU admission and case fatality rate (CFR) (p:0.4, p:0.6 and p:0.9, respectively).

CFR was $5.6 \%$ in patients without cancer, and it was $15.6 \%$ in HCT recipients. CFR was statistically different between groups $(p=0.001)$. In post-hoc analysis, the CFR in patients with HM was higher than the patients without cancer but there was no statistical difference between patients with HM and HCT recipients regarding CFR. Among 32 HCT recipients, five patients died. The characteristics of deceased HCT recipients are given in Table 3. The CFR in HCT recipients who were not receiving immunosuppressive agents at the time of COVID-19 diagnosis was $11.5 \%$, whereas it was $33 \%$ in HCT recipients who were receiving an immunosuppressive agent at the time of COVID-19 diagnosis.

The data about the course of COVID-19 in HCT recipients is based on case series. Huang et al. reported two posttransplant patients (transplant done for AML, 51 years old; and end-stage renal failure, 59 years old) on immunosuppressant and had stable graft function before COVID-19. The authors discontinued immunosuppressive agents and started methylprednisolone with prophylactic antibiotics. Both patients developed multiorgan failure and died [6]. Haroon et al. reported the clinical course of COVID-19 in their 11 transplant recipients aged between 11 and 60 years. Six of those patients had allo-HCT, four had auto-HCT and one patient had both allo and auto-HCT. They reported that none of the patients required MV [7]. In another case series including eight pediatric transplant recipients, researchers reported that two patients admitted to ICU and one patient died [8]. In a previous study, researchers reported the outcome of 25 patients with HM including 7 HCT recipients (5 autoHCT, 1 allo-HCT, 1 both allo and auto-HCT). Among all HCT recipients they reported that a 65 year old, male, MM patient who had auto-HCT history died [9].

As of May 12, 213 patients have been reported from 17 countries to European Society for Blood and Marrow Transplantation. Preliminary data showed $\sim 30 \%$ mortality in both allo and auto-HCT recipients [10].
In conclusion, our study reveals that HCT recipients, especially those receiving immunosuppressive drugs, constitute a special population of cancer patients, and physicians should effort great attention in the management of HCT recipients especially in those receiving immunosuppressive agents at the time of COVID-19 diagnosis. Due to the high infectivity of SARS-CoV-2, HCT recipients without COVID-19 should take their health services outside of the $\mathrm{CoV}$ pandemic hospitals. HCT centers should be isolated, and those patients' follow up should be continued with alternative ways such as teleconference systems as much as possible.

Turkish Ministry of Health, Hematology Scientific Working Group Fevzi Altuntas ${ }^{1,2}$, Naim Ata ${ }^{3}$, Tugçe Nur Yigenoglu ${ }^{1}$, Semih Bascı ${ }^{1}$, Mehmet Sinan $\mathrm{Dal}^{1}$, Serdal Korkmaz ${ }^{4}$, Sinem Namdaroglu ${ }^{5}$, Abdulkadir Basturk ${ }^{6}$, Tuba Hacıbekiroglu ${ }^{7}$, Mehmet Hilmi Dogu ${ }^{8}$, İlhami Berber ${ }^{9}$, Kursat $\mathrm{Dal}^{10}$, Mehmet Ali Erkurt ${ }^{9}$, Burhan Turgut ${ }^{11}$, Mustafa Mahir Ulgu ${ }^{12}$, Osman Celik ${ }^{13}$, Abdullah Akunal ${ }^{12}$, Suayip Birinci $^{14}$

Author contributions Concept and design: FA. Acquisition, analysis, or interpretation of data: MMU, AA. Drafting of the manuscript: FA. Critical revision of the manuscript for important intellectual content: All authors. Statistical analysis: SB.

\section{Compliance with ethical standards}

Conflict of interest The authors have no conflicts of interest to disclose.

Publisher's note Springer Nature remains neutral with regard to jurisdictional claims in published maps and institutional affiliations.

\section{References}

1. Yigenoglu TN, Ata N, Altuntas F, Basci S, Dal MS, Korkmaz S, et al. The outcome of COVID-19 in patients with hematological malignancy. J Med Virol. 2020. https://doi.org/10.1002/jmv. 26404.

2. Başcı S, Ata N, Altuntaş F, Yiğenoğlu TN, Dal MS, Korkmaz S, et al. Turkish Ministry of Health, Hematology Scientific Working Group. Outcome of COVID-19 in patients with chronic myeloid leukemia receiving tyrosine kinase inhibitors. J Oncol Pharm 
Pract. 20201078155220953198. https://doi.org/10.1177/1078155 220953198.

3. World Health Organization Press Conference. The World Health Organization (WHO) Has Officially Named the Disease Caused by the Novel Coronavirus as COVID-19. https://www.who.int/ emergencies/diseases/novel-coronavirus-2019. Accessed 30 May 2020.

4. Guan WJ, Ni ZY, Hu Y, Liang WH, Ou CQ, He JX, et al. Clinical characteristics of coronavirus disease 2019 in China. N. Engl J Med 2020;382:1708-20. https://doi.org/10.1056/NEJMoa 2002032.

5. Liang W, Guan W, Chen R, Wang W, Li J, Xu K, et al. Cancer patients in SARS-CoV-2 infection: a nationwide analysis in China. Lancet Oncol. 2020;21:335-7. https://doi.org/10.1016/ S1470-2045(20)30096-6.

6. Huang J, Lin H, Wu Y, Fang Y, Kumar R, Chen G, et al. COVID19 in posttransplant patients-report of 2 cases. Am J Transplant. 2020. https://doi.org/10.1111/ajt.15896.
7. Haroon A, Alnassani M, Aljurf M, Ahmed SO, Shaheen M, Hanbli A, et al. COVID-19 post hematopoietic cell transplant, a report of 11 cases from a single center. Mediterr J Hematol Infect Dis. 2020;12:e2020070. https://doi.org/10.4084/MJHID. 2020.070 .

8. Vicent MG, Martinez AP, Trabazo Del Castillo M, Molina B, Sisini L, Morón-Cazalilla G, et al. COVID-19 in pediatric hematopoietic stem cell transplantation: The experience of Spanish Group of Transplant (GETMON/GETH). Pediatr Blood Cancer. 2020:e28514. https://doi.org/10.1002/pbc.28514. [Epub ahead of print].

9. Malard F, Genthon A, Brissot E, Wyngaert Z, Marjanovic Z, Ikhlef S, et al. COVID-19 outcomes in patients with hematologic disease. Bone Marrow Transplant J. https://doi.org/10.1038/ s41409-020-0931-4.

10. EBMT. COVID-19 and BMT. 2020. https://www.ebmt.org/covid19-and-bmt. Accessed 28 May 2020.

\section{Affiliations}

Fevzi Altuntas $^{1,2} \cdot$ Naim $^{\text {Ata }}{ }^{3} \cdot$ Tugce Nur Yigenoglu $\mathbb{1}^{1} \cdot$ Semih Basci $^{1} \cdot$ Mehmet Sinan Dal $^{1} \cdot$ Serdal Korkmaz $^{4}$. Sinem Namdaroglu ${ }^{5}$ - Abdulkadir Basturk $\mathbb{1}^{6} \cdot$ Tuba Hacibekiroglu $^{7} \cdot$ Mehmet Hilmi Dogu $^{8} \cdot$ ilhami Berber $^{9}$. Kursat Dal ${ }^{10} \cdot$ Mehmet Ali Erkurt $^{9} \cdot$ Burhan Turgut $^{11} \cdot$ Mustafa Mahir Ulgu $^{12} \cdot$ Osman Celik $^{13}{ }^{13}$ Abdullah Akunal $^{12}$. Suayip Birinci ${ }^{14}$. On Behalf of Turkish Ministry of Health, Hematology Scientific Working Group

1 Department of Hematology and Bone Marrow Transplantation Center, Ankara Oncology Training and Research Hospital, University of Health Sciences, Ankara, Turkey

2 Department of Internal Medicine, Division of Hematology, Yıldırım Beyazıt University, Ankara, Turkey

3 Department of Strategy Development, Republic of Turkey, Ministry of Health, Ankara, Turkey

4 Department of Hematology, Kayseri Training and Research Hospital, University of Health Sciences, Kayseri, Turkey

5 Department of Hematology, Bozyaka Training and Research Hospital, University of Health Sciences, Izmir, Turkey

6 Department of Internal Medicine, School of Medicine, Division of Hematology, Selcuk University, Konya, Turkey

7 Department of Internal Medicine, School of Medicine, Division of Hematology, Sakarya University, Sakarya, Turkey
8 Department of Hematology, Istanbul Training and Research Hospital, İstanbul, Turkey

9 Department of Internal Medicine, School of Medicine, Division of Hematology, Inonu University, Malatya, Turkey

10 Department of Internal Medicine, Kecioren Training and Research Hospital, Ankara, Turkey

11 Department of Internal Medicine, School of Medicine, Division of Hematology, Namık Kemal University, Tekirdağ, Turkey

12 General Directorate of Health Information Systems, Republic of Turkey, Ministry of Health, Ankara, Turkey

13 Public Hospitals General Directorate, Republic of Turkey, Ministry of Health, Ankara, Turkey

14 Deputy Minister of Health, Republic of Turkey, Ankara, Turkey 